Revista de Negócios_ISSN 1980.4431_vol. 19, n. 1, p. 70_93, 2014_DOI:10.7867/1980431.2014v19n1p70_93

\title{
Estratégia dos negócios: Obstáculos encontrados para a consolidação da TV Digital no Brasil e seus impactos na cadeia produtiva eletroeletrônica na perspectiva da teoria dos stakeholders
}

\section{Business strategy: Obstacles to the consolidation of Digital TV in Brazil and its impact on electronics supply chain from the stakeholder theory view}

\author{
Roberto Bazanini \\ UNIP Universidade Paulista - Brasil \\ roberto.bazanini@terra.com.br \\ Hewdy Lobo Ribeiro \\ UNIP Universidade Paulista - Brasil \\ lobo@vidamental.com.br \\ Homero Leoni Bazanini \\ UNIP Universidade Paulista - Brasil \\ homerolbazanini@yahoo.com.br
}

\begin{abstract}
Recebido em 06 de maio de 2013. Alterado em 25 de julho de 2013. Aprovado em 27 de agosto de 2013.
Editor Responsável: Edson Roberto Scharf, Dr.

Processo de avaliação por double blind review
\end{abstract}

\begin{abstract}
Resumo
Com a implantação da TV Digital no Brasil em 02 de dezembro de 2007, os gestores da indústria de eletroeletrônicos, naturalmente, esperavam por impactos na cadeia produtiva em decorrência da promessa de forte aquecimento desse mercado. Por intermédio de pesquisa exploratória, de natureza qualitativa e entrevista em profundidade junto aos executivos da indústria de eletroeletrônicos, o objetivo da pesquisa está em diagnosticar os obstáculos encontrados para consolidação da TV Digital no Brasil e suas possíveis mudanças estratégicas com o surgimento de um novo cenário resultante das expectativas que se apresentavam no mercado brasileiro e suas implicações em termos de uma nova configuração do complexo eletroeletrônico na perspectiva da teoria dos stakeholders. Os resultados da pesquisa apontam que, na percepção dos pesquisados, embora as vendas de TV Digital tenham crescido acentuadamente nos últimos dois anos, na
\end{abstract}

perspectiva dos executivos da indústria de eletroeletrônicos, o processo ainda não se consolidou, as expectativas previstas não se concretizaram e, consequentemente, os impactos sobre a cadeia produtiva referente ao impacto que a TV Digital provocaria nessa indústria está num patamar abaixo do esperado em decorrência de fatores técnicos e associados, principalmente, aqueles relacionados à falta de integração dessa indústria junto aos stakeholders dominantes representados pelos radiodifusores e pelo governo federal. A contribuição da pesquisa está em discutir a aplicabilidade da teoria dos stakeholders no setor das telecomunicações em seus aspectos econômicos, técnicos e políticos. As limitações do trabalho se encontram no número reduzido dos sujeitos pesquisados e na ênfase em apenas um dos agentes envolvidos ao analisar o processo de consolidação da TV Digital no Brasil na perspectiva dos executivos da indústria eletroeletrônica, por isso, sugere-se para futuras 
Estratégia dos negócios: Obstáculos encontrados para a consolidação da TV Digital no Brasil e seus impactos na cadeia produtiva eletroeletrônica na perspectiva da teoria dos stakeholders

pesquisas estudos com os demais agentes fomentadores.

Palavras-chave: Estratégia dos Negócios. Indústria de Eletroeletrônicos. Stakeholders. Telecomunicações. TV Digital.

\begin{abstract}
With the introduction of digital TV in Brazil on December 2, 2007, the managers of the electronics industry, of course, waiting for impacts in the supply chain due to the promise of strong eating of the market. According with exploratory research, qualitative and in-depth interview with the executives of the electronics industry, the research objectivist diagnose the obstacles to consolidation of digital TV in Brazil and its possible strategic changes with the emergence of a new scenario resulting from the expectations that were in the Brazilian market and its implications in terms of a new configuration of complex electronics in the stakeholder theory view. The survey results indicate that, in the perception of respondents, while sales of digital TV have grown sharply in the past two years, from the perspective of industry executives from electronics, the process is not yet consolidated, provided the expectations did not materialize and hence the impact on the supply chain regarding the impact that digital TV would cause this industry sat a level below that expected by technical factors and associated mainly to the lack of integration with stakeholders definitive represented by broadcasters and the federal government. The contribution of the research is to discuss the applicability of the theory stakeholder's theory in the telecommunications sector in it's economic, technical and political. The limitations of the work lies in the small number of subjects studied and emphasis on only one of the agents involved and analyzes the process of consolidation of Digital TV in Brazil from the perspective of the consumer electronics industry executives, so it is suggested for future research studies with other agents developers.
\end{abstract}

Keywords: Electronics Industry; Stakeholder; Telecommunications; Digital TV.

\section{Introdução}

As Por ocasião da implantação da TV Digital no Brasil, em 02 de dezembro de 2007, os executivos das indústrias de eletroeletrônicos, em decorrência da escolha do padrão japonês, não tiveram plenamente seus interesses atendidos, visto que, idealmente, o padrão defendido por essa indústria era por uma tecnologia nativa pela possibilidade de produzir os próprios componentes no Brasil, sendo que, com a adoção do padrão japonês, coube a indústriaeletrônica brasileira apenas montar os componentes importados para a TV Digital, como afirma Cruz (2008, p. 15): “... foi uma vitória do poder político das emissoras de televisão sobre o poder econômico das empresas de telecomunicações".

As negociações sobre o modelo de TV Digital implantado no Brasil perduraram por mais de trezes anos (1994-2007) e só avançaram a partir da promulgação do decreto 4.901/03 em 2003, período no qual, a partir de então, as estratégias passaram a ser mais consistentes em virtude da Presidência da República haver instituído o Sistema Brasileiro de Televisão Digital (SBTD) juntamente com a criação do Comitê de Desenvolvimento, encarregado de estabelecer diretrizes para implantação do processo e, posteriormente, pela promulgação do decreto $5820 / 06$, em 02 de dezembro de 2007, que propiciou a outorga do padrão definitivo do sistema de TV digital terrestre na plataforma brasileira de radiodifusão de sons e imagens.

Os principais agentes envolvidos nesse processo podem ser divididos em seis grupos de stakeholders: Governo Federal Radiodifusores; Telecom); Indústria de Eletroeletrônicos, Consórcio de Academias e Coletivo Intervozes.

O Governo Federal - representado pelo comitê de desenvolvimento do SBTVD presidido pelo Ministério das Comunicações, Centro de Pesquisa e Desenvolvimento em Telecomunicações(CPqD) e Agência Nacional de Telecomunicações (ANATEL). Os Radiodifusores - empresas de comunicação lideradas pela Rede Globo de Televisão. Os Telecom engloba diversas empresas de comunicação em vários países. A indústria de eletroeletrônicos - empresas de fabricação dos componentes de geração, transmissão e recepção de conteúdos digitais. O Consorcio de Academias representado por diversas instituições, algumas com participação mais efetiva no 
processo, das quais se pode destacar: Universidade Federal de Pernambuco, PUC do Rio Grande do Sul, Universidade Presbiteriana Mackenzie, Escola Politécnica da USP, Universidade de Brasília, Universidade Federal de Minas Gerais.O Coletivo Intervozes, principal representante da sociedade civil, instituição formado por ativistas e profissionais com formação em Comunicação Social e em outras áreas, distribuídos em 15 estados brasileiros e no Distrito Federal, sendo que, cada associado do Intervozes é, ao mesmo tempo, um promotor de ações locais e um colaborador na formulação e realização de estratégias nacionais adotadas pelo coletivo.

Desde as primeiras discussões ocorridas, ainda na fase de préimplantação, cada um desses stakeholders estabeleceram alianças e elaboraram seus discursos em consonância com os interesses dos respectivos grupos que defendiam. Em virtude do dinamismo da disputa presente nos debates entre os agentes, na defesa de seus respectivos interesses, os atores foram modificando suas posições iniciais em decorrência da correlação de forças presentes no ambiente.

Posteriormente, transcorrida a fase de implantação (1994-2007), iniciou-se uma nova fase, a fase de consolidação da TV Digital no Brasil(2007-2016) em que os agentes certamente modificariam suas estratégias. Particularmente, em relação à indústria de eletroeletrônicos as expectativas estavam relacionadas ao aumento de vendas de televisores digitais e em decorrência, impactos na cadeia produtiva (AMATO, 2006).

Decorridos cinco anos da implantação, as expectativas da indústria de eletroeletrônicas foram parcialmente contempladas nos três últimos anos. Em 2010 ocorreu um aumento das vendas de aparelhos televisores com tecnologia digital, em grande parte impulsionada pela realização da Copa do Mundo na África do
Sul e principalmente pelo cenário econômico brasileiro atual, crescimento esse, que se manteve nos anos de 2011 e 2012. Atualmente, as expectativas mais promissoras estão voltadas para $2014 \mathrm{em}$ virtude da realização da Copa do Mundo ser realizada no Brasil.

Por meio de pesquisa exploratória, de natureza qualitativa, o objetivo da pesquisa está em fazer um diagnóstico dos obstáculos encontrados, a partir de 2007,para consolidação da TV Digital no Brasil na percepção dos executivos da indústria de eletroeletrônicos e, concomitantemente, discutir as principais mudanças ocorridas com o surgimento de um novo cenário resultante das perspectivas que se no mercado brasileiro e suas implicações em termos de uma nova configuração do complexo eletroeletrônico após a implantação da TV Digital no Brasil.

O problema central da pesquisa está em encontrar respostas para a questão: qual (is)o(s) obstáculo(s) encontrados para a consolidação da TV Digital no Brasil por parte da indústria eletroeletrônica em relação à atuação dos demais stakeholders?

A contribuição da pesquisa está em fornecer subsídios para melhor compreensão do papel dos agentes no processo de consolidação da TV Digital no Brasil, visto que, a teoria dos stakeholders possui raízes principalmente na sociologia, no comportamento organizacional e na política de interesses de grupos específicos, podendo ser definida, segundo Freeman e Mcvea (2000) como a formulação e implementação pelos administradores de processos que satisfaçam todos os grupos que tenham interesses em jogo na empresa.

\section{Revisão Bibliográfica}

Para efeitos didáticos, a revisão bibliográfica foi dividida em duas partes: publicações sobre o tema e referencial teórico. 
Estratégia dos negócios: Obstáculos encontrados para a consolidação da TV Digital no Brasil e seus impactos na cadeia produtiva eletroeletrônica na perspectiva da teoria dos stakeholders

\subsection{Publicações sobre o tema}

As publicações sobre o tema TV Digital apresentam características peculiares em sua fase de consolidação se comparados aos desenvolvidos na fase de implantação.

A maioria dos trabalhos acadêmicos sobre TV Digital no Brasil está relacionada ao período que precedeu sua implantação e as discussões que se estabeleceram entre os diferentes stakeholders. Dentre os vários trabalhos anteriores a implantação da TV Digital (1994-2007) pode-se destacar: Crocomo (2004); Montez e Becker (2005); Cruz (2006); Donato (2007). Em relação aos trabalhos acadêmicos após sua implantação, ou seja, na fase de consolidação da TV Digital no Brasil (a partir de 2007) pode-se destacar: Boni (2009), Ferreira (2010), Machado (2011), Cerozzi Ballan (2011), Zancanaro (2011), Thaler (2011) e Diniz (2012).

Numa primeira análise do teor desses trabalhos, em termos comparativos, pode-se constatar que as publicações anteriores ao período de implantação da TV Digital no Brasil (1994-2007)) privilegiam os aspectos técnicos, políticos e sociais, enquanto as publicações posteriores à implantação da TV Digital no Brasil (2008-2011) acentuam predominantemente somente os aspectos técnicos e educacionais em detrimento dos aspectos políticos e sociais.

Um das exceções dessa tendência pode ser encontrada em Domingues da Silva (2010), cuja análise, na vertente dos teóricos do Institucionalismo Histórico, enfatiza como o grupo dos radiodifusores se mostrou condutor informal do processo e atuou estrategicamente no sentido de ver seus interesses atendidos por meio de decisões governamentais. Nessa mesma linha de raciocínio, Chimenti et al (2012) promove questionamentos sobre a atuação da Rede Globo para atrair mais investimento publicitário e as dificuldades da emissora em lidar com a interatividade e gerir o relacionamento com seus consumidores.
Publicações internacionais, originárias dos Estados Unidos da América (cuja implantação da TV digital teve início em 2002 e encerramento das transmissões analógicas em 2009) analisam o impacto da democratização da informação em termos de recepção da mensagem e suas repercussões nas empresas de comunicação. Prior (2009) esclarece como a diversidade de canais distorcem as informações e impactam negativamente a audiência. Stroud (2010) enfatiza que, as pessoas podem escolher, sem quaisquer problemas de oferta de meios de comunicação pela diversidade de escolhas possíveis que refletem as suas predisposições políticas e visão de mundo. Webster e Ksiazek (2012) analisaram 236 meios de comunicação identificando camadas da atenção do público, ou seja, a democratização da informação em diferentes mídias resulta no alcance de pequenas audiências flutuantes, sugerindo uma distribuição em camadas da atenção do público, em vez de grupos isolados e público fiel, como era a visão predominante da publicidade e do marketing nos anúncios veiculados na TV analógica.

Portanto, a revisão da literatura apontou que a fragmentação da audiência na era digital, em seus aspectos técnicos e educacionais, provocam conseqüências econômicas, políticas e sociais que, para os propósitos da pesquisa, acompanhado dos referenciais teóricos relacionados às especificidades da indústria de eletroeletrônicos e a teoria dos stakeholders, na perspectiva da estratégia dos negócios,fornecem subsídios essenciais para a compreensão dos obstáculos encontrados para a consolidação da TV Digital no Brasil.

\subsection{Referencial teórico}

\subsubsection{A teoria dos stakeholders}

$\mathrm{O}$ referencial teórico para $\mathrm{o}$ desenvolvimento do presente trabalho encontra fundamentos nos campos de análise de stakeholders e competitividade do ambiente empresarial. Em virtude dos avanços teóricos, atualmente, não é 
possível estabelecer um conceito único sobre o significado dos stakeholders.

A teoria dos stakeholders utilizando-se dos mecanismos de análise da teoria sistêmica, referentes á interdependência e integração dos agentes que compõem um sistema procura explicar essa inter-relação e desenvolver fundamentação teórica atinente á responsabilidade social da organização com 0 ambiente onde está inserida. (CAMPBELL, 1997).

Wood (1990), Weiss (1998) e Frooman (1999), referem-se à definição de stakeholders, sugerida por Freeman (1984, p. 25) que é amplamente utilizada: stakeholders são indivíduos ou grupos que podem influenciar ou serem influenciados pelas ações, decisões, políticas, práticas ou objetivos da organização.

Ainda de acordo com Freeman (1984), o termo stakeholder surgiu pela primeira vez em 1963, aplicado à SRI Internationale, inicialmente, seu significado estava direcionado para estudar aqueles grupos que forneciam o apoio necessário para uma organização sobreviver. Em sua ótica a interação entre os diferentes stakeholders que influenciam o ambiente das organizações torna necessário que sejam desenvolvidos mecanismos que possibilitem entender essa interação. A busca por respostas que determinem não só o tipo de influência sofrida pelas ações desses grupos, como também como as organizações podem reagir às suas intervenções, pode tornar-se uma importante ferramenta auxiliar para tomada de decisões.

Entretanto, em relação às origens existem controvérsias: Preston (1990) considera que o aparecimento da abordagem de stakeholders, não necessariamente com essa denominação, ocorreu em 1933, portanto, trinta anos antes. Frooman (1999) argumenta que o desenvolvimento de uma análise de stakeholders deve responder três questões principais: a) Quem são os stakeholders da empresa?

Essa primeira questão refere-se aos atributos dos stakeholders;

b) O que os stakeholders buscam? Essa segunda questão refere-se aos objetivos dos stakeholders;

c) Quais as iniciativas que serão tomadas para alcançar esses objetivos?

Essa terceira questão refere-se aos métodos utilizados pelos stakeholders.

Greenwood (2001) apresenta vários tipos de qualificações que podem ser feitas para caracterizar os stakeholders como sendo: primários ou secundários, donos de capital ou não, de aspectos intangíveis ou tangíveis, possuidores de recursos ou dependentes dos recursos, de relacionamento voluntário ou involuntário.

Donaldson e Preston (1995) concebem os stakeholders como sendo grupos com interesses legítimos ou substanciais nos procedimentos e atividades corporativas. Esclarecem que não é necessário que a empresa considere todos os seus stakeholders, de maneira idêntica, durante o processo de decisão estratégica. Essa observação é importante já que existem críticas à teoria, como aquela proposta por Steinberg (1996), de que seria impossível dar a mesma importância ou tratar igualmente os interesses de todos os stakeholders.

Todavia, ao se admitir o conceito amplo é preciso ter cautela em relação aos interesses e as influências de todos os stakeholders. Para tanto, deve ser levado em conta que cada stakeholder possui uma diferente importância e um diferente poder frente à organização. É necessário, pois, entender que cada organização possui diferentes stakeholders e, principalmente, cada organização é influenciada por cada grupo de stakeholders de uma maneira diferente. Como saber então, qual é essa 
Estratégia dos negócios: Obstáculos encontrados para a consolidação da TV Digital no Brasil e seus impactos na cadeia produtiva eletroeletrônica na perspectiva da teoria dos stakeholders

influência?

Ackerman e Eden (2003) apontam técnicas que ajudam a analisar e gerenciar os stakeholders considerando-os toda sua complexidade, cuja importância está em detalhar a importância de cada stakeholder e estudar seus interesses e papéis na organização.

Segundo Windsor (1999), há correntes que defendem que múltiplos interesses, conforme prescritos na teoria dos stakeholders podem ser balanceados, inclusive com o benefício de obterem as partes vantagens mútuas. Por outro lado, outros argumentam que interesses podem ser concorrentes e eventualmente conflitantes, não sendo possível, portanto, atendê-los sem que haja prejuízo para alguma das partes.

Desde as primeiras discussões sobre o modelo de TV Digital a ser implantado no Brasil, os seis principais agentes fomentadores tiveram papel determinante na defesa de seus interesses, conforme quadro 1.

Quadro 1 - Discursos dos Stakeholders da TV Digital no Brasil

\begin{tabular}{|l|l|}
\hline Agente Fomentador & \multicolumn{1}{|c|}{ Interesses e Objetivos } \\
\hline Governo Federal & $\begin{array}{l}\text { - Integração e desenvolvimento: propiciar educação à distância, telemedicina, } \\
\text { disseminação cultural, comércio eletrônico, serviços bancários, informações sob } \\
\text { demanda, bate-papo e correio eletrônico. }\end{array}$ \\
\hline Radiodifusores & $\begin{array}{l}\text { - Interesses predominantemente comerciais: levar conteúdo em alta definição de } \\
\text { som e imagens e manter o modelo de negócio atual, baseado na venda de } \\
\text { audiência para os anunciantes. }\end{array}$ \\
\hline Sociedade Civil & $\begin{array}{l}\text { - Democratização da informação: a importância do acesso à informação, } \\
\text { entretenimento e interatividade a todos os segmentos da sociedade. }\end{array}$ \\
\hline $\begin{array}{l}\text { Indústria de } \\
\text { Eletroeletrônico }\end{array}$ & $\begin{array}{l}\text { - Interesses predominantemente comerciais: impulsionar as vendas de televisores e } \\
\text { celulares no país. }\end{array}$ \\
\hline $\begin{array}{l}\text { Indústria de } \\
\text { Telecomunicações }\end{array}$ & $\begin{array}{l}\text { - Interesses predominantemente comerciais: implantar o padrão Europeu de TV } \\
\text { Digital (DVB), uma vez que esse padrão representa seus interesses comerciais e já } \\
\text { está estabelecida em mais de cinquenta países disseminado entre Europa, Ásia, } \\
\text { África, Oceania e Oriente Médio. }\end{array}$ \\
\hline Consórcio das Academias & \begin{tabular}{l} 
Interesse pela pesquisa:desenvolver um padrão com tecnologia nacional. \\
\hline
\end{tabular}
\end{tabular}

Fonte: Bazanini (2009).

O quadro acima busca atender aos questionamentos propostos por Frooman (1999): Quem são os stakeholders da empresa? O que os stakeholders buscam? Quais as atitudes que serão tomadas para alcançar esses objetivos?

Em seu conjunto, os seis stakeholders possuem interesses distintos que em alguns pontos são harmônicos e em outros, conflitantes.

De modo geral, logicamente as atitudes que serão tomadas para alcançar esses objetivos estarão em consonância com osinteresses de cada um dos agentes, sendo que, regra geral se alinham aos interesses do governo federal pela necessidadede integração e desenvol- vimento que, de certa forma, beneficiam todos os envolvidos. Por outro ladoos interesses dos radiodifusores ao buscar oportunidades para ampliar seus privilégios comerciais, por exemplo, são antagônicos em relação aos interesses de outros stakeholders pelo esforço em manter o padrão de programação atual do modelo analógico para não pulverizar a publicidade, o que prejudica acentuadamente os interesses do Coletivo Intervozes, do Consórcio das Academiase em menor grau os interesses do Telecom e da Indústria eletroeletrônica.

A tipologia sociológica por Mitchell, Agle \& Wood (1997) denominado Salience Modelpermite a 
identificação dos atores chave de um projeto, uma avaliação dos seus interesses e da influência destes interesses no risco e na viabilidade do projeto, ao qualificar os diferentes tipos de agentes de acordo com certa hierarquia, todavia ressalta que é importante entender a totalidade das interações dos stakeholders entre si, já que, por exemplo, determinado grupo que não é vital para organização pode gerar influência em grupos que são vitais pela avaliaçãode seu poder, legitimidade e urgênciana organização. Osautores acima conceituam tais construtos da seguinte forma:

1. Atributo do Poder: pode ser definidocomo a capacidadedostakeholder paraimpor sua vontade. Trata da existência ou possibilidade de obtenção por um ator social por intermédio de recursos coercitivos (força física, armas), recursos utilitários (tecnologia, dinheiro, conhecimento, logística, matérias primas) e recursos simbólicos (prestígio, estima, carisma) para impor sua vontade sobre outro(s) em uma relação (jogo social).

2. Atributo de Legitimidade: pressuposição ou percepção generalizada de que as ações de um ator social (pessoa, organização, marca, símbolo etc.) são desejáveis ou apropriadas dentro de certos sistemas socialmente construídos de normas, valores, crenças e definições. É evidente que este conceito de legítimo como socialmente desejável, oriundo de Suchman (1995), implica no reconhecimento de que os atores sociais nem sempre têm claramente definido o que é desejável em certas circunstâncias.

3. Atributo de Urgência: Consiste no clamor por atenção imediata em função de diferentes graus de sensibilidade temporal da não aceitação do atraso; criticalidade, ou a importância do clamor tendo em vista a possibilidade de dano à propriedade, sentimento, expectativa e exposição.

Todavia, Mitchell, Agle e Wood (1997, p. 867), advertem que o conceito de urgência “... existe somente quando duas condições são encontradas: (1) quando uma relação ou reclamação é de natureza sensível ao tempo e (2) quando esta relação ou reclamação é importante ou crítica para o stakeholder.

Genericamente, a combinação desses três atributos (Poder, Legitimidade e Urgência) em diferentes composições leva a sete tipos de stakeholders, agrupados em três categorias de stakeholders: latentes, expectantes e definitivos (MITCHEL, AGLE E WOOD, 1997).

Os stakeholders latentes possuem apenas um dos atributos da tríade (poder, legitimidade, urgência). Podem ser classificados em adormecidos, exigentes e discricionários.

- Stakeholders Adormecidos: poder sem legitimidade e urgência. $\mathrm{O}$ poder coercitivo do Estado, muito dinheiro ou a influência da mídia podem não servir para nada, se os detentores destes recursos não têm urgência e se o interesse não é legítimo. O essencial para estes stakeholders é a possibilidade de adquirirem um segundo atributo (legitimidade ou urgência).

- Stakeholders Exigentes: urgência sem poder e legitimidade tornam estes stakeholders barulhentos e incômodos apenas.

- Stakeholders Discricionários: com legitimidade, mas sem urgência e poder. A atenção a esta categoria de stakeholder depende do reconhecimento discricionário da organização, o que normalmente se dá em bases filantrópicas.

Os stakeholders expectantes possuem dois dos atributos da tríade (Poder, Legitimidade, Urgência). Podem ser classificados em perigosos, dominantes e dependentes.

- Stakeholders Perigosos: urgência e poder sem legitimidade. Há, neste caso, espaço para o uso da coerção por esta categoria de stakeholder, sob a forma de aquisições hostis, sabotagem, greve, terrorismo etc.

- Stakeholders Dominantes: com poder e legitimidade fazem parte da coalizão 
Estratégia dos negócios: Obstáculos encontrados para a consolidação da TV Digital no Brasil e seus impactos na cadeia produtiva eletroeletrônica na perspectiva da teoria dos stakeholders

dominante na organização. Portanto, seus interesses e expectativas fazem diferença para a organização.

- Stakeholders Dependentes: urgência e legitimidade sem poder torna esta categoria de stakeholders dependente do poder de outros stakeholders, de dentro ou de fora da organização de forma a terem seus interesses atendidos ou não segregados.

Os stakeholders definitivos possuem os três atributos da tríade (Poder, Legitimidade e Urgência), ou seja, são antigos stakeholders expectantes que, ao reunirem o atributo que faltam, seus interesses passam a ser prioritários sobre os demais.

Portanto, na concepção Salience Model (Mitchel, Agle \& Wood, 1997), atores que não reúnem pelo menos um destes atributos (não afetam os resultados e/ou não são afetados pelos resultados), não são considerados stakeholders.

\section{Metodologia}

Esse estudo se caracteriza por pesquisa exploratória, de natureza qualitativa com análise dos resultados voltada para a técnica da Análise de Conteúdo (Bardin, 2002).

O objetivo da pesquisa, em sua essência, é definido por Boyd (2001, p. 5) como: “... descobrir respostas para perguntas, através do emprego de processos científicos.".

A pesquisa surge, então, como um instrumento auxiliar na busca de informações sobre determinado assunto quando estas não se encontram disponíveis ou organizadas num nível que permita sua utilização.

Boyd $(2001,7)$ é de opinião, ainda, que se realizem pesquisas em função de duas necessidades básicas: razões de ordem intelectual ou razões de ordem prática. Godoy $(1995,58)$ esclarece que a diferenciação entre essas duas abordagens:
Enquanto a pesquisa quantitativa se caracteriza como um estudo com o qual o pesquisador conduz seu trabalho a partir de um plano estabelecido a priori, com hipóteses claramente especificadas e variáveis operacionalmente definidas e preocupa-se com a quantificação dos resultados, com a precisão da medida, a pesquisa qualitativa não procura enumerar elou medir os eventos estudados, nem emprega instrumental estatístico, e sim, parte de questões e focos de interesses amplos, que se vão definindo à medida que o estudo se desenvolve. Nesse caso, na abordagem qualitativa, o relacionamento pesquisado entre as variáveis em estudo depende muito mais da perspicácia da observação do pesquisador do que de algoritmos matemáticos, estatísticos ou de qualquer natureza quantitativa. enfatiza:

$$
\text { Godoy }(1995,58) \text { prossegue e }
$$

Apesar das diferenças entre as abordagens qualitativa $e$ quantitativa, no caminho para a busca dos objetivos, mesmo que possuam contornos diferentes, em ambas, a pesquisa se caracteriza como um esforço cuidadoso para a descoberta de novas informações ou relações e para a verificação $e$ ampliação do conhecimento existente.

Por sua vez, Cervo e Bervian (1996, 158-159) tecem considerações referentes em quais situações se deve recorrer à entrevista:

\footnotetext{
Quando se há de recorrer à entrevista? Recorre-se à entrevista quando não há fontes mais seguras para as informações desejadas ou quando se quiser completar dados extraídos de outras fontes. A entrevista possibilita registrar, além disso, observações sobre a aparência, sobre o comportamento $e$ as atitudes do entrevistado. Daí sua vantagem sobre o questionário.
} 
Segundo Bardin (2002, 75) no emprego da análise de conteúdo é possível situar um número de observações formuláveis a título de hipóteses provisórias:

Uma primeira leitura, quer seja "flutuante" - leitura intuitiva, muito aberta a todas as ideias, reflexões, hipótese, numa espécie de "brainstorming" individual quer seja parcialmente organizada, sistematizada, com o auxílio de procedimentos de descoberta, permite situar certo número de observações formuláveis, a título de hipóteses provisórias.

Por se tratar de um estudo exploratório qualitativo, não é o objetivo deste trabalho estabelecer as relações de causa e efeito. O caminho escolhido é a entrevista em profundidade com os executivos das indústrias de eletroeletrônicos. Considerando que a abordagem qualitativa, enquanto exercício de pesquisa, não se apresenta como uma proposta rigidamente estruturada, permite que a imaginação e a criatividade levem os investigadores a propor trabalhos que explorem novos enfoques (Godoy, 1995).

A metodologia qualitativa de pesquisa, segundo Ludke (1986), é o estudo que se desenvolve numa situação natural, é rico em dados descritivos, apresenta um plano aberto e focaliza a realidade de forma complexa e contextualizada.

A postura científica provém da prática de um método científico, aplicável a qualquer tema. Nessa pesquisa, o estudo será exploratório, pois, devido ao assunto ora proposto não ter uma base limitada de resultados de pesquisas anteriores, a ênfase será dada à descoberta de práticas ou diretrizes que precisam modificar-se e na elaboração de alternativas que possam ser substituídas.

O objetivo da pesquisa está em diagnosticar os obstáculos encontrados para consolidação da TV Digital no Brasil e suas possíveis mudanças estratégicas com o surgimento de um novo cenário resultante das expectativas que se apresentavam no mercado brasileiro e suas implicações em termos de uma nova configuração do complexo eletroeletrônico na perspectiva da teoria dos stakeholders.

O problema central da pesquisa está em encontrar respostas para a questão: qual (is) o(s) obstáculo(s) encontrados para a consolidação da TV Digital no Brasil por parte da indústria eletroeletrônica em relação à atuação dos demais stakeholders?

A amostra por conveniência com 2 diretores de empresa de eletroeletrônicos que participaram das discussões sobre a implantação da TV Digital no Brasil desde 1994 e continuam empenhados em diversos projetos de inovação junto aos demais stakeholders.

As respostas dos entrevistados foram transcritas literalmente, para posteriormente, seus resultados serem apresentados de forma sintética na forma de quadros. Por solicitação dos próprios entrevistados, as respostas foram codificadas em E1 (entrevistado 1) e E2 (entrevistado 2). E1 consentiu que fosse divulgado apenas o seu cargo (diretor comercial de empresa multinacional de eletroeletrônicos). E2 autorizou a divulgação do seu cargo e sua última formação acadêmica (diretor geral de empresa multinacional de eletroeletrônicos, formado em administração pela Universidade de Harvard).

Assim, após a realização da pesquisa documental e bibliográfica, foi realizada a pesquisa de campo, com o intuito de identificar na concepção dos executivos de duas grandes empresas de eletroeletrônicos, o processo de consolidação da TV Digital no Brasil, por meio de entrevista com questões não estruturadas, conforme quadro 2. 
Estratégia dos negócios: Obstáculos encontrados para a consolidação da TV Digital no Brasil e seus impactos na cadeia produtiva eletroeletrônica na perspectiva da teoria dos stakeholders

Quadro 2 - Questões propostas.

1. Decorridos mais de três anos da Implantação da TV Digital, as expectativas do setor eletroeletrônico foram atendidas?

2. Que medidas serão necessárias para a consolidação da TV Digital no Brasil?

3. Que tipos de alianças serão necessárias entre a indústria de eletroeletrônicos e os demais agentes fomentadores?

4. Como a indústria de eletroeletrônicos concebe o futuro da TV Digital no Brasil? Você acredita, conforme previsão do governo federal, que até 2016, o sistema de transmissão será cem por cento digital?

5. A adoção do padrão japonês pode ser considerada equivocada?

6. Atribua nota de 0-10 para os atributos dos demais agentes em termos do grau de poder, grau de legitimidade e grau de urgência.

Fonte: os autores.

As limitações da pesquisa se encontram principalmente na quantidade dos elementos da amostra que, embora os entrevistados estivessem envolvidos em projetos de inovação desde as primeiras discussões sobre o padrão de TV Digital implantado no Brasil a partir de 02 de dezembro de 2007.

\section{Resultados da Pesquisa}

Inicialmente, a pesquisa bibliográfica e documental, de forma genérica, possibilitaram constatar as especificidades das estratégias empregadas na industria de eletroeletrônicos e as tendências do mercado de televisores no Brasil a partir de 2008. Posteriormente, as respostas dos entrevistados na pesquisa de campo foram submetidas ao tratamento da técnica de Análise de Conteúdo (Bardin, 2002) para, finalmente, serem analisadas na perspectiva da abordagem Salience Model dos stakeholders (Mitchel, Agle \& Wood).

\subsection{Especificidades da Indústria de Ele- troeletrônicos}

A definição de um Sistema Brasileiro da TV Digital desencadeia a possibilidade de ocorrência de uma série de impactos em toda a cadeia produtiva da indústria eletrônica, incluindo as empresas produtoras do produto acabado (televisores e equipamentos de recepção e demais acessórios), assim como em toda a cadeia de fornecedores (fabricantes de peças, componentes, equipamentos, instalações e demais insumos, serviços técnicos especializados como de assistência técnica). Tal fato implica, também, na necessidade de requalificação e treinamento profissional, além de provocar outros tipos de impactos do ponto de vista da pesquisa industrial e do sistema Ciência, Tecnologia e Inovação como um todo.

A televisão digital surge como uma maneira de incorporar novas tecnologias a uma mídia já consagrada, aumentando a atratividade e o potencial competitivo da televisão, ao oferecer uma melhoria considerável na qualidade da imagem e do som, pelo fato de eliminar ruídos de sinal, e oferecendo serviços diferenciados como transmissão de vários programas em um só canal, acesso à Internet, interatividade e recepção móvel. A partir desta nova tecnologia, a indústria de televisores concebe uma possibilidade de expandir mercados e de se recuperar do declínio na produção nos últimos anos, através da oferta de novos produtos: o televisor digital e o set-top box, aparelho conversor de sinais digitais para analógicos, que permite que um televisor comum receba a transmissão digital.

Desde a implantação da TV Digital no Brasil os conversores passaram a ser vendidos separadamente dos aparelhos de $\mathrm{TV}$, sendo que, somente a partir de março de 2011, por força de lei, os conversores 
passaram a ser embutidos na TV Digital.

\subsubsection{As diferentes estratégias das empresas da indústria eletroeletrônica}

Segundo (Baptista, 1993; Gouveia, 2003) é possível identificar diferentes formas de inserção competitiva por parte das empresas que atuam no mercado da eletrônica de consumo. No que se referem às estratégias das empresas, três tipos de estratégias podem ser encontradas: estratégia de liderança tecnológica, estratégia de baixo custo e estratégia intermediária.

\subsubsection{Estratégia de liderança tecnológica}

A estratégia de liderança tecnológica é típica das grandes empresas líderes em seus respectivos segmentos de mercado, que realizam permanentemente significativos investimentos em P\&D, direcionados, principalmente, à introdução de novos produtos em seus estágios iniciais do ciclo de vida. São exemplos típicos desta categoria de empresas: as japonesas Matsushita (proprietária das marcas
Panasonic, National, Technics, Quasar e Ramsa, Sony, Sharp, Toshiba e Hitachi, a holandesa Philips e a francesa Thompson Multimedia.

\subsubsection{Estratégias de baixo custo}

As estratégias de baixo custo geralmente são empregadas pelas empresas especializadas em manufatura (contractmanufacturers), que priorizam as elevadas escalas de produção, cujos processos são mais intensivos em trabalho. Em geral estão localizadas em países de baixos salários. Exemplos de empresas como essas são as indústrias eletrônicas de países asiáticos (inclusive as chinesas) e as maquiladoras mexicanas.

\subsubsection{Estratégias intermediárias}

As estratégias intermediárias estão presentes nas empresas entre as duas primeiras categorias, que têm como principal objetivo a conquista de nichos de mercado pouco explorados pelas líderes em tecnologia, conforme quadro 3.

Quadro 3 - Definição de tipos de estratégias na indústria de bens eletrônicos de consumo.

\begin{tabular}{|c|c|c|c|}
\hline \multicolumn{2}{|c|}{ Desafiante não-pioneira } & Desafiante pioneira & First-mover \\
\hline Entrada & Baixo custo & Liderança tecnológica & \multirow{3}{*}{ Liderança tecnológica } \\
\hline Mid-fi & Intermediária & & \\
\hline$H i-f i$ & $\begin{array}{l}\text { Intermediária } \\
\text { Liderança tecnológica }\end{array}$ & & \\
\hline
\end{tabular}

Fonte: O próprio autor com base em Gouveia (2003).

a. Segmento de entrada: se refere àquele cujo principal mote concorrencial se encontra no fator preço e a diferenciação do produto se dá por conta de funções acessórias.

b. Segmento mid-fi (ou middlefidelity): em que se verificam estratégias de marketing global e renovação continuada na linha de equipamentos, com inovações de recursos e design; neste caso, as escalas globais de produção permitem a redução dos custos, em geral acompanhada por boa oferta de serviços pelos fabricantes.

c. Segmento hi-fi (ou high-fidelity): consiste na faixa de mercado em que os aparelhos visam a reprodução ou gravação de som, imagem ou ambos com alto grau de fidelidade frente ao fenômeno real. 
Estratégia dos negócios: Obstáculos encontrados para a consolidação da TV Digital no Brasil e seus impactos na cadeia produtiva eletroeletrônica na perspectiva da teoria dos stakeholders

As estratégias desse mercado são altamente segmentadas para se alcançar basicamente as inovações de ruptura e as inovações de sustentação. Lieberman e Montgomery (1988) reuniram literatura teórica e empírica que descrevem as vantagens dos desafiantes pioneiros, os primeiros entrantes no mercado (first mover) e dos desafiantes não pioneiros (late mover) em termos dos tipos de liderança concorrenciais atualmente empregadas.

No primeiro, as vantagens estão relacionadas principalmente à liderança tecnológica em produtos e processos acompanhados de bens escassos e desenvolvimento de custos ao comprador de trocas de fornecedor, no segundo, a liderança intermediária, a principal vantagem se encontra capacidade da empresa lançar produtos concorrentes similares com preços atrativos e, ainda, pouco explorados pelos líderes em tecnologia.

Esses aspectos concorrenciais presentes na liderança tecnológica e liderança intermediária foram ilustrados por Kim e Mauborgne (2005) com a utilização de metáforas "oceano azul" e "águas vermelhas". Essas metáforas explicam o investimento em inovações de ruptura, ou seja, aquelas ações com objetivo de criar "oceanos azuis", que causam maior impacto no lucro das empresas, se comparado com as "águas vermelhas", isto é, inovações de sustentação que limita-se a acrescentar melhorias dos mercados existentes.

Em ambos os casos, a inovação se constitui em requisito imprescindível para a competitividade, seja da empresa na condição de desafiante pioneira ou não pioneira.

No mercado de produtos eletroeletrônicos, um dos exemplos mais instrutivos da aplicabilidade das estratégias de desafiante pioneira pode ser encontrado na Samsung. A empresa, uma das principais fabricantes de produtos eletrônicos do mundo e há sete anos líder no segmento de TVS digitais, foi colocada por Hamman (2012) em patamar de igualdade com a Apple no quesito inovação ao criar estratégias e investir em produtos de sucesso em TVS, celulares, PDAs, enfim, especializou-se em equipamentos digitais, semicondutores, memória e sistema integrado, tornando-se, assim, pioneira em tecnologia para geração, transmissão e recepção de conteúdos.

Comumente, essas estratégias, diante das novas regras do jogo desse novo mercado da TV Digital se voltam para a inovação tecnológica, conteúdo interativo e estratégias inovadoras de mercado, com procedimentos não diferem muito de outros setores da atividade econômica. Todavia, no mercado de novas mídias, deve-se considerar a convergência das três telas acompanhada da inovação do conteúdo interativo voltado para a nova TV, a TV Inteligente ou a TV Digital Interativa que envolve a cadeia produtiva da TV Digital.

\subsubsection{A cadeia produtiva da TV Digital}

A cadeia produtiva da TV Digital abrange diversos setores da economia e não somente as emissoras e os fabricantes de televisores. $\mathrm{O}$ conceito de cadeia produtiva envolve todos os setores que estão relacionados por algum ramo da televisão digital, seja em maior ou em menor grau.

Na perspectiva tecnológica, é possível desmembrar a cadeia da TV Digital, sob uma em três grandes blocos, que seriam geração, transmissão, recepção, conforme figura 1 . 


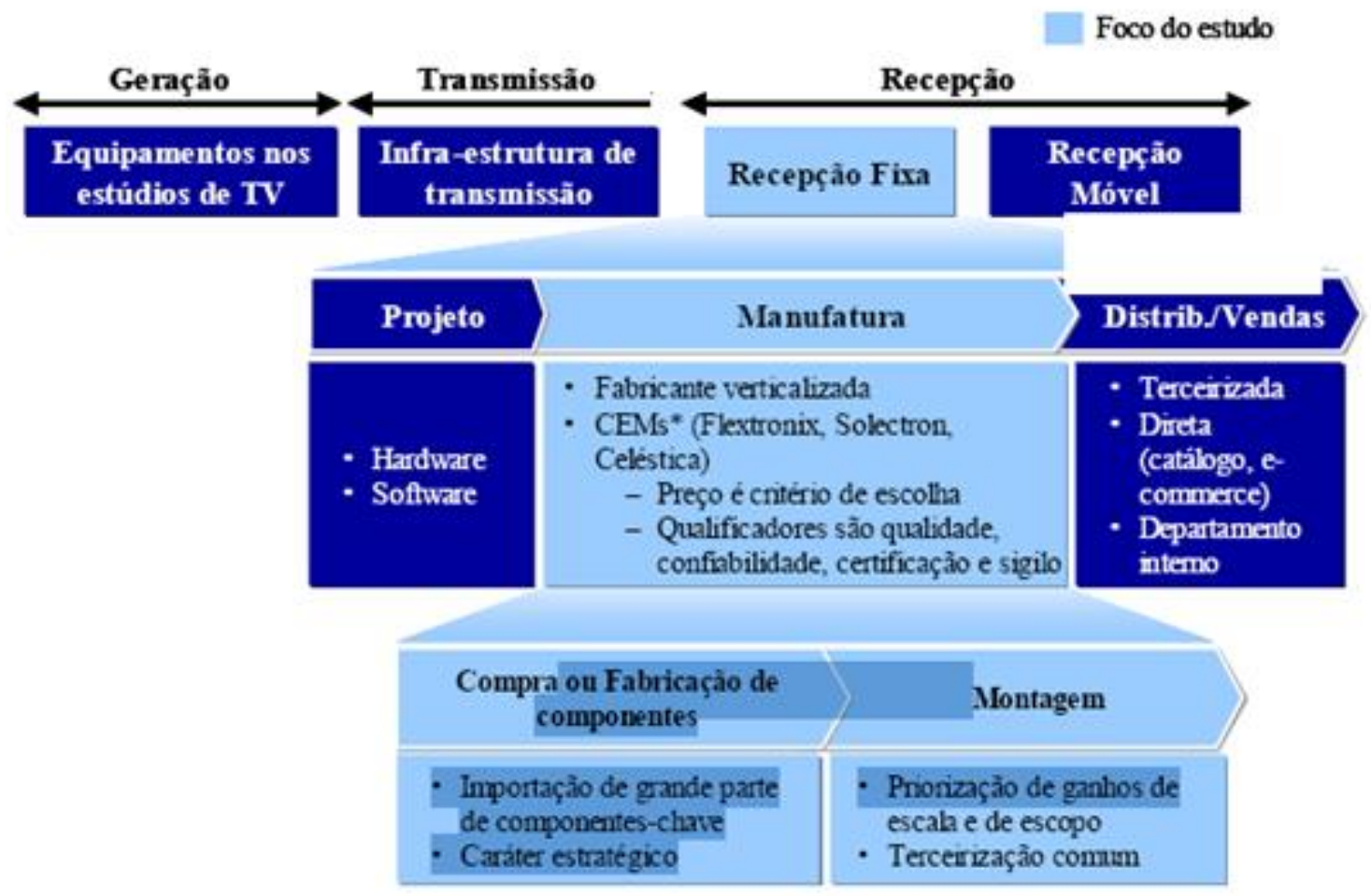

* Contract Equipment Mamufacturer, fibricantes terceirizados de componentes ou bens finais

Figura 1 - Cadeia da TV Digital

Fonte: Amato Neto et al. (2004).

De modo geral, pode-se afirmar que a geração, a transmissão e a recepção formam a base dos componentes eletrônicos fornecidos por essa indústria.

A geração: aprofundando este elo, envolve a produção de conteúdo, englobando a fabricação dos equipamentos para tal e toda a cadeia de fabricação dos mesmos, além de toda a rede de serviço das emissoras.

A transmissão: engloba a fabricação dos equipamentos de transmissão e também das antenas, além das chamadas retransmissoras de sinais, que possuem normalmente uma pequena "base" instalada além da antena.

A recepção: envolve a fabricação dos equipamentos que têm como destino o usuário final do produto televisão e a distribuição dos mesmos, sejam eles de recepção fixa ou móvel. Além disso, abrange a futura oferta de serviços que virão com a televisão por trás destes serviços.
Nesses três grandes blocos a indústria eletroeletrônica colocou sua expectativa de crescimento na dependência das vendas de televisores com tecnologia digital para o mercado brasileiro.

\section{20 mercado de televisores}

O mercado de televisores sofreu profundas alterações na concorrência das empresas do setor com o surgimento da TV Digital. Empresas tradicionais perderam mercado: a Gradiente sucumbiu no mercado digital; a Philips abandonou o mercado de TVs em abril de 2011, após enfrentar seguidos prejuízos; a Sony perdeu mercado para as concorrentes sul coreanas Samsung e LG.

As expectativas da Indústria eletroeletrônica, por ocasião da implantação da TV Digital no Brasil, em 2007, estiveram relacionadas ao aquecimento do mercado de televisores.

Desde então, as vendas dos televisores digitais (TV com tela de LCD) cresce- 
Estratégia dos negócios: Obstáculos encontrados para a consolidação da TV Digital no Brasil e seus impactos na cadeia produtiva eletroeletrônica na perspectiva da teoria dos stakeholders

ram significativamente, os televisores com tela de plasma estacionaram desde 2010. O crescimento nas vendas de televisores com tela plana e LCD foram constantes e acentuadas desde 2008. A partir de 2010 houve um aumento significativo nas vendas de televisores, em grande parte, impulsionado pela realização da Copa do Mundo e principalmente pelo cenário econômico favorável, como se observa na tabela 1 .

Tabela 1 - Quantidade de Televisores Vendidos

\begin{tabular}{|c|c|c|c|c|c|c|}
\hline & 2008 & 2009 & 2010 & 2011 & 2012 & \begin{tabular}{|l|} 
Variações \\
Percentuais \\
\end{tabular} \\
\hline $\begin{array}{l}\text { TV em cores - } \\
\text { Analógico }\end{array}$ & 8.152 .662 & 5.296 .789 & 3.600 .167 & 2.732 .542 & 1.215 .561 & $\begin{array}{l}(-35,03 \%) \\
(-32,03 \%) \\
(-24,10 \%) \\
(-55,52 \%) \\
\end{array}$ \\
\hline $\begin{array}{l}\text { TV com Tela de } \\
\text { Plasma }\end{array}$ & 292.401 & 332.571 & 433.241 & 403.181 & 426.873 & $\begin{array}{l}(+13,73 \%) \\
(+30,26 \%) \\
(+6,94 \%) \\
(+5,88 \%) \\
\end{array}$ \\
\hline $\begin{array}{l}\text { TV com Tela de } \\
\text { LCD }\end{array}$ & 2.435 .237 & 3.977 .612 & 8.033 .514 & 10.950 .610 & 12.721 .929 & $\begin{array}{l}(+63,33 \%) \\
(+102 \%) \\
(+36,31 \%) \\
(+16,12 \%) \\
\end{array}$ \\
\hline
\end{tabular}

Fonte: SUFRAMA (2013).

Tabela 2 - Faturamento

\begin{tabular}{|c|c|c|c|c|c|c|}
\hline US\$ (Milhões) & 2008 & 2009 & 2010 & 2011 & 2012 & $\begin{array}{l}\text { Variações } \\
\text { Percentuais }\end{array}$ \\
\hline $\begin{array}{l}\text { TV em cores - } \\
\text { Analógico }\end{array}$ & 1.630 & 957 & 646 & 478 & 181 & $\begin{array}{l}(-41,29 \%) \\
(-32,50 \%) \\
(-26,01 \%) \\
(-62,13 \%)\end{array}$ \\
\hline $\begin{array}{l}\text { TV com Tela de } \\
\text { Plasma }\end{array}$ & 302 & 301 & 406 & 372 & 333 & $\begin{array}{l}(-0,33 \%) \\
(+34,85 \%) \\
(-8,37 \%) \\
(-10,48 \%) \\
\end{array}$ \\
\hline $\begin{array}{l}\text { TV com Tela de } \\
\text { LCD }\end{array}$ & 2.320 & 2.922 & 5.682 & 6.744 & 6.516 & \begin{tabular}{|l}
$(+25,94 \%)$ \\
$(+94,45 \%)$ \\
$(+18,69 \%)$ \\
$(-3,38 \%)$
\end{tabular} \\
\hline
\end{tabular}

Fonte: SUFRAMA (2013).

Surpreendentemente, para a indústria de eletroeletrônicos, o faturamento das vendas com televisores LCD em 2012 foi inferior ao ano de 2011.

Em relação à quantidade produzida, as empresas de eletroeletrônicos estão reduzindo a produção de televisores analógicos e aumentando acentuadamente a produção de televisores com tela de LCD no decorrer dos últimos quatro anos, confor- 
Homero Leoni Bazanini

me tabela 3 .

Tabela 3 - Quantidade Produzida

\begin{tabular}{|c|c|c|c|c|c|c|}
\hline & 2008 & 2009 & 2010 & 2011 & 2012 & $\begin{array}{l}\text { Variações } \\
\text { Percentuais }\end{array}$ \\
\hline $\begin{array}{l}\text { TV em cores } \\
- \text { Analógico }\end{array}$ & 7.978.759 & 4.905 .961 & 3.608 .820 & 2.588 .372 & 1.081 .991 & $\begin{array}{l}(-38,51 \%) \\
(-26,44 \%) \\
(-28,28 \%) \\
(-58,20 \%)\end{array}$ \\
\hline $\begin{array}{l}\text { TV com Tela } \\
\text { de Plasma }\end{array}$ & 332.707 & 313.196 & 427.387 & 407.542 & 440.830 & $\begin{array}{l}(-5,86 \%) \\
(+36,45 \%) \\
(-4,64 \%) \\
(+8,17 \%) \\
\end{array}$ \\
\hline $\begin{array}{l}\text { TV com Tela } \\
\text { de LCD }\end{array}$ & 2.667 .101 & 3.816 .966 & 8.160 .800 & 10.868 .833 & 12.195 .412 & $\begin{array}{l}(+43,11 \%) \\
(+113,8 \%) \\
(+33,18 \%) \\
(+12,20 \%)\end{array}$ \\
\hline
\end{tabular}

Fonte: SUFRAMA (2013).

A TV de LCD acabou superando a TV de plasma por razões tecnológicas. As TVs com tela de plasma são indicadas para ambientes em que é possível controlar a intensidade de luz, o que favorece toda fidelidade de cores e alto contraste do plasma. Em ambientes mais claros, os reflexos na tela podem atrapalhar bastante e prejudicar a principal qualidade do aparelho, por isso, Atualmente, as TVs mais modernas no mercado brasileiro são os modelos de LED. Na prática, uma TV de LED é uma TV LCD, todavia, a iluminação traseira da tela é feita por LEDs, e não por lâmpadas do tipo fluorescente, usadas nas LCDs convencionais. Essa substituição torna possível fabricar aparelhos bem mais finos. Para modelos com até 55 polegadas, há TVs com apenas 3 centímetros de espessura. Assim como as TVs de LCD, os aparelhos de LED se adaptam a qualquer ambiente e condições de luminosidade.

Em termos mercadológicos, podese notar que o aquecimento do mercado aponta para a importância dos megaeventos. $\mathrm{O}$ crescimento registrado entre 2009 e 2010, confirma a tendência da TV Digital se consolidar nos próximos anos no Brasil, principalmente, em decorrência da Copa do Mundo em 2014, fato esse, que pode concorrer para o "apagão analógico" em 2016, conforme previsão do governo federal.

\subsection{Percepção dos executivos da Indús- tria de eletroeletrônicos}

Os resultados da pesquisa de campo apontam que, na percepção dos executivos da indústria de eletroeletrônicos entrevistados, o obstáculo determinante para a consolidação da TV Digital no Brasil e seus impactos na cadeia produtiva da indústria eletroeletrônica está na dependência da atuação dos stakeholders definitivos (governo federal e radiodifusores) que determinam os rumos desse crescimento.

Com o intuito de melhor esclarecer os entraves e possibilidades para consolidação da TV Digital no Brasil, para o tratamento dos dados a técnica da análise temática ou categorial foi utilizada a 
Estratégia dos negócios: Obstáculos encontrados para a consolidação da TV Digital no Brasil e seus impactos na cadeia produtiva eletroeletrônica na perspectiva da teoria dos stakeholders

técnica da Análise de Conteúdo que, de acordo com Bardin (2002), baseia-se em operações de desmembramento do texto em unidades, ou seja, descobrir os diferentes núcleos de sentido que constituem a comunicação, e posteriormente, realizar o seu reagru- pamento em classes ou categorias.

Com base nas respostas da pesquisa pode-se inferir que, na concepção dos executivos das indústrias de eletro-eletrônicos, a TV Digital ainda não se consolidou, conforme quadro 4.

Quadro 4 - Análise das respostas e palavras-chave.

\begin{tabular}{|c|c|c|}
\hline \multicolumn{3}{|l|}{ ENTREVISTA } \\
\hline PERGUNTAS & RESPOSTAS & $\begin{array}{l}\text { PALAVRAS- } \\
\text { CHAVE }\end{array}$ \\
\hline $\begin{array}{l}\text { 1. Decorridos mais de três anos } \\
\text { da Implantação da TV Digital, as } \\
\text { expectativas do setor } \\
\text { eletroeletrônicos foram } \\
\text { atendidas? }\end{array}$ & $\begin{array}{l}\text { E1.Em parte sim, em parte não. O crescimento } \\
\text { poderia ter sido bem maior se os radiodifusores } \\
\text { e o governo federal fossem mais efetivos em } \\
\text { suas ações. } \\
\text { E2. Evidentemente que não. Os maiores } \\
\text { obstáculos para uma maior penetração da TV } \\
\text { Digital no Brasil foi o preço do conversor, a } \\
\text { programação, a pouca iteratividade e até } \\
\text { mesmo a falta de informação quanto à } \\
\text { cobertura da transmissão. }\end{array}$ & $\begin{array}{l}\text { Principais obstáculos: } \\
\text {. Preço do conversor } \\
\text { - monoprogramação } \\
\text {. Pouca interatividade } \\
\text {. Falta de informação } \\
\text { para o público }\end{array}$ \\
\hline $\begin{array}{l}\text { 2. Que medidas serão } \\
\text { necessárias para a consolidação } \\
\text { da TV Digital no Brasil? }\end{array}$ & $\begin{array}{l}\text { E1. Algumas medidas já foram tomadas, outras } \\
\text { ainda precisam ser tomadas. Em relação ao } \\
\text { preço do conversor, esse problema não existirá } \\
\text { mais a partir de } 2012 \text { pelo conversor embutido } \\
\text { no próprio aparelho, ou seja, "o ginga } \\
\text { embarcado”. No que diz respeito à } \\
\text { programação, um dos requisitos mais } \\
\text { importantes está na quebra da verticalização da } \\
\text { programação, ou seja, o espectador poderá } \\
\text { controlar o conteúdo e a hora de exibição do } \\
\text { programa. Essa mudança cabe ao radiodifusor. } \\
\text { Em relação à interatividade, é preciso } \\
\text { esclarecer que interatividade promoverá um } \\
\text { novo modo de assistir à TV, criando uma } \\
\text { forma de interação entre a programação e o } \\
\text { telespectador. Interatividade está "diretamente } \\
\text { ligada aos novos media digitais. O que } \\
\text { compreendemos hoje por interatividade, é o } \\
\text { que chamamos de uma nova forma de interação } \\
\text { técnica, de cunho ‘eletrônico digital’”, } \\
\text { diferenciando da interação analógica, que } \\
\text { caracteriza os meios tradicionais. Com isso, } \\
\text { podemos questionar se é possível chamarmos } \\
\text { de TV interativa aquela em que o espectador do } \\
\text { programa responde sim ou não, ou ainda, } \\
\text { participa de algum tipo de enquete, pois, nesses } \\
\text { casos não há uma participação que modifica e } \\
\text { produz conjuntamente um conteúdo, mas sim } \\
\text { que formata opções pré-determinadas. A TV } \\
\text { dita digital hoje ainda não possui nada de } \\
\text { interativo. Ela é meramente reativa, apenas } \\
\text { podemos escolher opções, participar por e- } \\
\text { mails, mas nada de interferir e ter um papel } \\
\text { ativo em relação à programação, quando }\end{array}$ & $\begin{array}{l}\text { Medidas a serem } \\
\text { tomadas } \\
\text {. Redução no preço do } \\
\text { conversor. } \\
\text {. Promover a } \\
\text { interatividade. } \\
\text {. Implantar a } \\
\text { multiprogramação. }\end{array}$ \\
\hline
\end{tabular}




\begin{tabular}{|c|c|c|}
\hline & $\begin{array}{l}\text { deixará de ser uma comunicação unidirecional. } \\
\text { A falta de informação da população sobre o } \\
\text { funcionamento da TV Digital constitui um dos } \\
\text { grandes entraves para a consolidação das } \\
\text { vendas da televisão digital junto ao grande } \\
\text { público. } \\
\text { E2. Vem se consolidando. Os radiodifusores } \\
\text { precisam ter vontade política. A } \\
\text { monoprogramação tem que ser substituída pela } \\
\text { multiprogramação. Todavia, isso não interessa } \\
\text { aos radiodifusores. É preciso divulgar o que e } \\
\text { como funciona a TV Digital. Deveria haver } \\
\text { uma divulgação maciça. A partir de } 2011 \text { todos } \\
\text { os televisores com o conversor embutido fará o } \\
\text { preço cair, o que, certamente, favorecerá o } \\
\text { apagão analógico previsto para } 2016 \text {. }\end{array}$ & \\
\hline $\begin{array}{l}\text { Que tipos de alianças serão } \\
\text { necessárias para a indústria de } \\
\text { eletroeletrônicos junto aos } \\
\text { demais agentes fomentadores? }\end{array}$ & $\begin{array}{l}\text { E1. No início foi montada uma aliança } \\
\text { coerente. Ao longo do prazo cada agente } \\
\text { fomentador foi mudando seu discurso. Estavam } \\
\text { todos unidos, porem com o passar do tempo } \\
\text { cada um defendeu o seu interesse. A aliança } \\
\text { que almejamos é aquela que conseguiria } \\
\text { minimizar o valor das peças, diminuindo as } \\
\text { taxas de importação junto ao governo federal. } \\
\text { E2. Qualquer aliança para ser efetiva passa pela } \\
\text { negociação com o governo federal e os } \\
\text { radiodifusores. A indústria de eletroeletrônicos } \\
\text { sofre diretamente as consequências das } \\
\text { medidas tomadas ou não tomadas pelos } \\
\text { radiodifusores e governo federal. A redução de } \\
\text { impostos sobre os componentes importados } \\
\text { contribuiria para reduzir o preço dos televisores }\end{array}$ & $\begin{array}{l}\text { Alianças com o } \\
\text { governo federal e } \\
\text { radiodifusores. }\end{array}$ \\
\hline $\begin{array}{l}\text { Como a indústria de } \\
\text { eletroeletrônicos concebe o } \\
\text { futuro da TV Digital no Brasil? } \\
\text { Conforme previsão do governo } \\
\text { federal, até } 2016 \text {, o sistema de } \\
\text { transmissão será cem por cento } \\
\text { digital. Isso será possível? }\end{array}$ & $\begin{array}{l}\text { E1. Bastante promissor desde que os } \\
\text { componentes importados sejam barateados, } \\
\text { haja divulgação em massa do funcionamento } \\
\text { da TV Digital e, apoio do governo. Tudo } \\
\text { depende do governo federal. O apagão } \\
\text { analógico para } 2016 \text { é perfeitamente possível. } \\
\text { E2. A TV Digital é uma realidade no mundo } \\
\text { todo. Vivemos na era da tecnologia. Com a } \\
\text { obrigatoriedade do conversor embutido a partir } \\
\text { de } 2012 \text {, certamente, em } 2016 \text {, os televisores } \\
\text { serão digitais. }\end{array}$ & $\begin{array}{l}\text { Futuro Promissor } \\
\text { (Depende do governo } \\
\text { federal e dos } \\
\text { radiodifusores) }\end{array}$ \\
\hline $\begin{array}{l}\text { A adoção do padrão japonês } \\
\text { pode ser considerada } \\
\text { equivocada? }\end{array}$ & $\begin{array}{l}\text { E1. Nunca em hipótese alguma. Seria melhor o } \\
\text { padrão cem por cento nacional. Tudo } \\
\text { importado. Montam no brasil. Alguns } \\
\text { componentes são fabricados aqui. O chip-set é } \\
\text { importado. } \\
\text { E2. Para indústria não importa o sistema, mas } \\
\text { sim, estar introduzido na nova tecnologia e o } \\
\text { aumento de vendas Entretanto, ainda temos } \\
\text { obstáculos para uma maior penetração da TV } \\
\text { Digital no Brasil quanto ao preço do conversor, } \\
\text { a programação, a pouca iteratividade e até } \\
\text { mesmo a falta de informação quanto à }\end{array}$ & Decisão acertada \\
\hline
\end{tabular}


Estratégia dos negócios: Obstáculos encontrados para a consolidação da TV Digital no Brasil e seus impactos na cadeia produtiva eletroeletrônica na perspectiva da teoria dos stakeholders

\begin{tabular}{|l|l|l|}
\hline & cobertura da transmissão. Em parte sim, em & \\
parte não. O crescimento poderia ter sido bem & \\
maior. Os maiores obstáculos para uma maior & & \\
penetração da TV Digital no Brasil foi o preço & & \\
do conversor, a programação, a pouca & iteratividade e até mesmo a falta de informação & \\
quanto à cobertura da transmissão. & \\
\hline
\end{tabular}

Fonte: elaborado pelo autor.

Após a análise das respostas dos executivos da Indústria de eletroeletrônicos foi possível especificar mais detalhada- mente os fatores determinantes para a consolidação da TV Digital do Brasil na visão desse agente, conforme quadro 5.

\section{Quadro 5 - Fatores determinantes para Consolidação}

PRINCIPAIS OBSTÁCULOS. Preço do conversor, monoprogramação, pouca iteratividade; falta de informação quanto ao funcionamento da TV Digital; cobertura da transmissão. Os radiodifusores e o governo federal precisam informar a população sobre o funcionamento da TV Digital, esse, na concepção dos executivos entrevistados constitui um dos grandes entraves para a consolidação das vendas da televisão digital junto ao grande público.

ALIANÇAS NÃO REALIZADAS. As alianças inicialmente estabelecidas, com o passar do tempo, cada agente fomentador foi mudando seu discurso, defendendo seu interesse pessoal.

ALIANÇAS E ACORDOS NECESSÁRIOS. Os radiodifusores e o governo federal precisam informar a população sobre o funcionamento da TV Digital, esse, na concepção dos executivos entrevistados constitui um dos grandes entraves para a consolidação das vendas da televisão digital junto ao grande público. Em virtude da maioria dos componentes serem importados, as indústrias de eletroeletrônicos reivindicam junto ao governo federal, as diminuições das taxas de importação desses componentes.

FUTURO PROMISSOR. O futuro da TV Digital no Brasil é concebido como promissor, sendo que os executivos entrevistados acreditam que em 2016, o sistema brasileiro será cem por cento digital.

MEDIDAS JÁ TOMADAS. Algumas medidas necessárias para a consolidação da TV Digital no Brasil já foram tomadas, outras ainda precisam ser tomadas. A partir de 2011 os televisores passaram a ser vendidos com o conversor embutido no próprio aparelho, ou seja, "o ginga embarcado".

MEDIDAS NÃO TOMADAS. Em relação à verticalização da programação, ou seja, o controle do conteúdo pelo telespectador ainda não se realizou. Essa mudança cabe ao grupo de radiodifusores que não manifestou maior interesse em alterar sua programação. A interatividade caminha de forma bastante lenta, a interatividade real é aquela que permite a modificação dos próprios conteúdos pelos telespectadores.

SINTESE: O futuro da TV Digital pode ser bastante promissor, se essas medidas e alianças forem concretizadas. As alianças necessárias para a consolidação da TV Digital no Brasil passam pela atuação do governo federal e dos radiodifusores. O governo federal pela redução dos impostos de importação e os radiodifusores pela adoção da multiprogramação, da real interatividade e uma campanha de esclarecimento para a população.

Fonte: elaborado pelo autor.

Em relação à questão 6 referente ao grau de poder e grau de urgência dos stakeholders para a consolidação da TV
Digital no Brasil, os resultados apresentaram as seguintes médias, conforme tabela 4.

Tabela 4 - Análise do poderio dos Stakeholders

\begin{tabular}{|l|l|l|l|l|}
\hline Stakeholder & Poder & Legitimidade & Urgência & Classificação \\
\hline Governo Federal & 10 & 10 & 10 & Stakeholder definitivo \\
\hline Radiodifusores & 10 & 10 & 10 & Stakeholder definitive \\
\hline Telecom & 4 & 6 & 8 & Stakeholder expectante e perigoso \\
\hline Indústria de eletroeletrônicos & 3 & 5 & 8 & Stakeholder expectante e dependente \\
\hline
\end{tabular}




\begin{tabular}{|l|l|l|l|l|}
\hline Coletivo Intervozes & 3 & 6 & 2 & Stakeholder latente e discricionário \\
\hline Consórcio das Academias & 2 & 6 & 6 & Stakeholder latente e exigent \\
\hline
\end{tabular}

Fonte: autor com base na tipologia de Mitchel, Agle e Wood (1997).

\section{Discussão dos resultados}

Decorridos mais cinco anos de sua implantação, a consolidação da TV Digital no Brasil ainda não ocorreu pelos obstáculos que ainda não foram superados e, consequentemente, as expectativas iniciais da Indústria de eletroeletrônicos realizou-se abaixo do esperado.

O preço do conversor, considerado um dos principais obstáculos detectados pelos executivos da Indústria de eletroeletrônicos, parece ter sido solucionado com a obrigatoriedade da inclusão do aparelho no próprio televisor por imposição do governo federal, a partir de 2011, entretanto, essa solução pouco contribuiu para o aumento das vendas, visto que, o crescimento das vendas dos televisores LCD de 2011 para 2012 foi de apenas $16,12 \%$.

É interessante observar que na fala dos entrevistados em nenhum momento se faz referência ao crescimento nas vendas em decorrência da Copa do Mundo, embora, a análise dos dados da pesquisa (tabela 1, 2, 3) aponte que o crescimento do mercado de televisores ocorre nas vésperas dos megaeventos como a disputa do Campeonato Mundial de Futebol.

Os entrevistados concebem que a consolidação da TV Digital no Brasil passa necessariamente pela atuação do governo federal e dos radiodifusores. $\mathrm{Na}$ perspectiva da teoria dos stakeholders, os radiodifusores e governo federal na condição de stakeholders definitivos são dominantes, visto que possuem os atributos do poder, legitimidade e urgência, portanto, comandam o ritmo em que se dará a consolidação da TV Digital no Brasil.

Por isso, a falta de desenvolvimento, soluções adequadas e disponíveis para a TV Digital relacionadas à programação, abrangência de sinal, canal de retorno e equipamentos padronizados ainda impedem o seu crescimento no Brasil.

Donaldson\& Preston (1995) enfatizam que a gestão baseada nos stakeholders deve dedicar atenção simultânea aos stakeholders mais importantes, tanto no estabelecimento da estrutura organizacional como nas políticas gerais e na tomada de decisões. Corroborando essa posição, com base no pensamento de Mitchell, Agle\& Wood (1997), é possívelconceber queos demais agentes fomentadores que, de certo modo, podem influenciar a cadeia produtiva da indústria de eletroeletrônicos podem ser classificados da seguinte forma, conforme quadro 6.

Quadro 6 - Classificação dos stakeholders da TV Digital

\begin{tabular}{|l|l|}
\hline Governo Federal & Stakeholderdefinitivo (poder- legitimidade - urgência) \\
\hline Radiodifusores & Stakeholder definitivo (poder- legitimidade - urgência) \\
\hline Coletivo Intervozes & Stakeholder latente e discricionário \\
\hline Telecom & Stakeholder expectante e perigoso \\
\hline Indústria de Eletroeletrônicos & Stakeholder expectante e dependente \\
\hline Consórcio das Academias & Stakeholder latente e exigente \\
\hline
\end{tabular}

Fonte: elaborado pelos autores com base em Mitchell, Agle e Wood (1997). 
Estratégia dos negócios: Obstáculos encontrados para a consolidação da TV Digital no Brasil e seus impactos na cadeia produtiva eletroeletrônica na perspectiva da teoria dos stakeholders

O Governo Federal e Radiodifusores sendo stakeholders definitivos possuem os três atributos da tríade (Poder, Legitimidade e Urgência), ou seja, são antigos stakeholders expectantes que, ao reunirem $o$ atributo que falta, seus interesses passam a ser prioritários sobre os demais. O Coletivo Intervozes na condição de stakeholders latentes e discricionários, possui apenas legitimidade; Os Telecom, stakeholders expectantes e perigosos possuem influência relativa, visto que, possuem poder e legitimidade; a Indústria de Eletroeletrônicos, stakeholders expectantes e dependentes estão na dependência dos stakeholders definitivos; o mesmo ocorrendo com o Consórcio de Academias, stakeholders, latentes e exigentes.

Desde as primeiras discussões entre os agentes fomentadores, as conquistas e os avanços da TV Digital, bem como os entraves para consolidação, estiveram sempre na dependência direta dos stakeholders definitivos. A obrigatoriedade do conversor embutido nas vendas dos televisores digitais, proporcionados pelo governo federal e radiodifusores, a partir de 2011 constitui uma conquista da indústria de eletroeletrônicos pela redução dos preços dos televisores, apesar de se considerar que, um dos maiores entraves está no pouco esclarecimento sobre o funcionamento da TV Digital, problema esse, que está na alçada do governo federal e radiodifusores.

Outros entraves revelados na pesquisa, como a interatividade e a multiprogramação não atendem os interesses dos radiodifusores que pretendem manter a mono programação tradicional. Estabelece-se, nesse particular, conflito de interesses entre os interesses antagônicos do governo federal e dos radiodifusores em relação à indústria de eletroeletrônicos.

Nesse particular, as pesquisas desenvolvidas (Prior, 2009; Stroud, 2010;
Webster e Ksiagek, 2012) são bastante esclarecedoras ao ressaltar a atenção seletiva do receptor decorrentes da tecnologia digital e seus impactos nas empresas de comunicação.

Transportados para a realidade brasileira, os impactos nas empresas de comunicação seriam acentuados, caso a multiprogramação fosse adotada. Na fase anterior a implantação, o Decreto 4901/03 prejudicava os interesses comerciais dos proprietários das mídias televisivas, fato esse que acarretou sérias divergências em relação aos interesses dos radiodifusores que buscavam manter seu modelo de negócio baseado em publicidade, visto que, o referido decreto privilegiava a pulverização da mídia, possibilitando, dessa maneira, a inserção de novos players. Embora substituído pela publicação do Decreto 5820/06, o Coletivo Intervozes, ainda sim, insistia na necessidade da multiprogramação.

Se o governo tivesse obrigado as emissoras a dividir um mesmo canal digital, como fez a Europa, haveria uma sobra maior de canais, que poderiam ser usados por novas emissoras privadas, públicas e estatais. Ao invés de SBT 1, SBT 2, SBT 3 e SBT 4, poderíamos ter o mesmo SBT de hoje e mais três novas emissoras. Assim, o Decreto Presidencial 5.820 estaria cumprindo a Constituição Federal, que, em seu artigo 220, veda qualquer forma de forma de monopólio e oligopólio no rádio e na TV (COLETIVO INTERVOZES, 2007, p. 25).

Contudo, apesar de ser vedado constitucionalmente o monopólio e oligopólio no rádio e na TV, a obrigatoriedade das emissoras dividirem um mesmo canal digital provocaria a fragmentação da audiência e a 
pulverização de conteúdos. Para esses, o retorno ideal é aquele que possa remunerar toda cadeia da comunicação com audiência bastante elevada dentro de uma só programação, daí a importância da monoprogramação para se manter os interesses dos radiodifusores. Por essa razão, os esforços são direcionados para investir todo o capital em conteúdos diferenciados de alto valor e alto desejo pela população, e não um volume imenso para alcançar pequenas audiências.

Desse modo, contrariamente aos interesses dos radiodifusores, por ocasião da escolha do padrão japonês para a TV Digital no Brasil, o Coletivo Intervozes, defensor da democratização da informação e, portanto, da multiprogramação, sempre manifestou críticas veementes ao modo como se deu essa escolha, tanto em seu aspecto econômico quanto em seu aspecto político (FNDC, 2005). Contudo, o Coletivo Intervozes, na condição de stakeholders latentes e discricionários possuem apenas legitimidade (desprovido de poder e urgência), por isso, talvez,esse stakeholdernão foi sequer mencionado pelos executivos das empresas eletroeletrônicos como importante para a consolidação da TV Digital no Brasil.

Evidencia-se, portanto, que as disputas e negociações ocorridas entre os principais agentes fomentadores durante a fase de implantação da TV Digital no Brasil, tende a prosseguir na fase de consolidação. Se, por um lado, para os radiodifusores, os Telecom, as indústrias de eletroeletrônicos o mercado seria altamente estimulado nos anos vindouros, por outro, para o Coletivo Intervozes e para o Consórcio das Academias, as decisões do governo federal ao adotar o modelo japonês favoreceu os radiodifusores e sabotaram as expectativas da sociedade civil, as previsões não se concretizaram e, desse modo, novas estratégias, alianças e negociações, certamente, se tornarão necessárias.

Enfim, a interatividade da TV
Digital não ocorreu de forma plena. Por ocasião da implantação da TV Digital em dezembro de 2007, a promessa era que seria possível ter serviços parecidos com os da internet na TV aberta, tais como: acessar informações sobre a programação, últimas notícias, condições do trânsito e previsão do tempo, participar de enquetes e jogos, consultar extrato bancário, pagar contas e até fazer compras, ao alcance do controle remoto, dentre outras facilidades.

Todavia, apesar desses entraves, estamos diante de dois megaeventos desportivos em nosso país: a Copa do Mundo em 2014 e os Jogos Olímpicos em 2016, acontecimentos esses, que tendem a contribuir fortemente para o aumento das vendas de televisores e respectivos agregados.

O caso da Indústria eletroeletrônica se constitui em instrutivo exemplo da aplicabilidade da teoria dos stakeholders no sentido de explicar os efeitos dos interesses stakeholders definitivos sobre os demais agentes no contexto da competitividade empresarial.

\section{Referências}

ACKERMANN, F. e EDEN, C. Powerful and interested stakeholders matter: their identification and management. Academy of Management Best ConferencePaper. 2003.

AMATO, J. Análise da emergência da TV digital e seus impactos na cadeia produtiva eletroeletrônica brasileira. Chile, Universidad Alberto Hurtado. Journal of Technology Management \& Innovation, v. 1, n. 5, p. 53-68, 2006.

AMATO Neto, J.; Garcia, R. C.; Fontes, C. B. V.; ANGRISANO, C. e JUNQUEIRA, C. H. Z. 2004. Impactos da definição do Sistema Brasileiro de TV Digital na cadeia produtiva da indústria eletrônica - Fase I. Relatório de pesquisa REDECOOP/ PRO-EPUSP/ Fundação 
Estratégia dos negócios: Obstáculos encontrados para a consolidação da TV Digital no Brasil e seus impactos na cadeia produtiva eletroeletrônica na perspectiva da teoria dos stakeholders

Vanzolini/ Departamento de Engenharia Rede Globo de Televisão.

BARDIN, L. Análise de Conteúdo. Lisboa: Edições 70, 2002.

BAPTISTA, M. A. C. Competitividade da Indústria de Bens Eletrônicos de Consumo. Nota Técnica Setorial do Complexo Eletrônico do Estudo da Competitividade da Indústria Brasileira. Mimeo. Consórcio IE/Unicamp, IEI/UFRJ, FDT, FUNCEX - MCT, FINEP e PADCT, Campinas, 1993.

BAZANINI, R. Posicionamento Estratégico dos Agentes Fomentadores na Implantação da TV Digital no Brasil. Disputas, Negociações e Estratagemas Retóricos. Revista de Negócios, ISSN 1980-4431, Blumenau, v. 14, n. 3 Julho/Setembro 2009, p. 1 -34.

BONI, F. A. TV Digital: O aparelho de representação do real na edição de imagens no telejornalismo, 2009. Dissertação (Mestrado em Comunicação) Universidade Estadual de Londrina, Londrina, 2009.

BOYD JR.; HARPER S.; WESTFALL, R. Método Científico e Projeto de Pesquisa. São Paulo: Pioneira, 2001.

CAMPBELL, A. Stakeholders. The Case in Favour. Long Range planning, London, v. 30, n. 3, p. 446-449. 1997.

CEROZZI BALAN, W. A Imagem e a Composição Visual Na TV Digital. Dissertação de Mestrado. São Bernardo do Campo, UMESP, 2011.

CERVO, A. L.; BERVIAN, P. A. Metodologia Científica. 4. ed. São Paulo: Makron Books, 1996.

CHIMENTI, P. C. P. S.; NOGUEIRA, A. R. R.; RODRIGUES, M.; VAZ, L.F.H. e ARKADER, R.A Rede Globo e o Desafio da TV Digital no Brasil. In: XXXVI EnANPAD, 2012, Rio de Janeiro. Anais do XXXVI EnANPAD. Rio de Janeiro: ANPAD, 2012. v. 1.

COLETIVO INTERVOZES. Concessões de rádio e TV: onde a democracia ainda não chegou.Coletivo Brasil de Comunicação Social, nov. 2007. Disponível em: <http://www.intervozes.org.br/publicacoes /revistas-cartilhas-manuais/revista_conces soes_web.pdf/view>. Acesso em: $21 \mathrm{dez}$. 2012.

CROCOMO, F.A. TV Digital Produção Interativa: A Comunidade Recebe e Manda Notícias. Tese de Doutorado. Universidade Federal de Santa Catarina, 2004.

CRUZ, R. TV Digital no Brasil. Tecnologia versus política. São Paulo, Senac, 2008.

Fora da Caixa: o processo de decisão sobre o sistema de TV Digital no Brasil. Tese de doutorado. São Paulo, USP, 2006.

DINIZ, R. H. L. A TV Digital e o setor industrial tecnológico brasileiro. Dissertação de Mestrado, São Bernardo do Campo, UMESP, 2012.

DOMINGUES DA SILVA, Juliano. A política da política de TV digital no Brasil: desenho institucional e judicialização do debate. In: Anais do XXXIII Congresso Brasileiro de

Ciências da Comunicação (Intercom 2010), Caxias do Sul, RS, 2 a 6 set. 2010.

DONALDSON, T.; PRESTON, L.E. The Stakeholder Theory of the Corporation: Concepts, Evidence, and Implications. Academy of Management Review. v. 20, n.1, p.65-91, 1995.

DONATO, M. Estratégias de posicionamento e disputas na implantação da TV Digital no Brasil. Dissertação de Mestrado. São Paulo, Facasper, 2007.

FERREIRA, G. D. Um Middleware Declarativo Ginga-NCL na Plataforma Android para o Sistema Brasileiro de Televisão Digital. (SBTVD). Dissertação de Mestrado. PPGI/UFES, 2010. 
FNDC. FÓRUM NACIONAL PELA DEMOCRATIZAÇÃO DA COMUNICAÇÃO. O que o governo despreza no debate sobre a TV Digital: elementos para recuperação do interesse público no projeto estratégico da digitalização das comu-nicações no Brasil. FNDC: Brasília, 2005.

FREEMAN, E. R. Strategic Management. A Stakeholder Approach. Boston, Pitman Publishing Inc.m, 1984.

FREEMAN, R. E.; McVEA, J. A stakeholder approach to strategic management. In: HITT, M.; FREEMAN, E.; HARRISON, J. Handbook of Strategic Management. Oxford: Blackwell Publi-shing, 2000.

FROOMAN, J. Stakeholder influence strategies. Academy of Management Review. v.24, n.2, p. 191-205, 1999.

GODOY, A. S. A pesquisa qualitativa e sua utilização em administração de empresas. São Paulo: Revista de Administração de Empresas, v.35. n. 4, p.65-71, jul/ago 1995.

GREENWOOD, M. The importance of Stakeholders according to business leaders. Businessand Society Review. V. 106, n 1, p. 29-49, 2001.

GOUVEIA, F. Eletrônicos de Consumo: Relatório Setorial Preliminar. Rede DPPFINEP, São Paulo, 2003.

HAMMAN, R. (2012). Samsung: a nova Apple do pedaço [infográfico]. Disponível em: <http://www.tecmundo.com.br/infogra fico/18196-samsung-a-nova-apple-do-peda co-infografico-.htm>. Acesso em: 01/05/2013.

KIM, W. Chan; MAUBORGNE, Renée. A Estratégia do Oceano Azul: como criar novos mercados e tornar a concorrência irrelevante. Rio de Janeiro, Campus, 2005.

LIEBERMAN; M. B. e MONTGOMERY, D. B. First-Mover (Dis)Advantages: Retrospective and Link with the Resource
Based View. Strategic Management Journal, v. 19, n.12, p. 1111-1125, Dez., 1998.

LÜDKE, M.; ANDRÉ, M. E. D. A. Pesquisa em educação: abordagens qualitativas. São Paulo: EPU, 1986.

MACHADO, F. Acessibilidade Na Televisão Digital: Estudo para uma política de Audiodescrição na televisão brasileira. Dissertado de Mestrado, São Paulo,UNESP de Bauru, 2011.

MITCHELL, R., AGLE, B. e Wood, D. Toward a theory of stakeholder identification and salience: defining the principle of who and what really counts. Academy of Management Review, v.22, n.4, p. 853-886, 1997.

MONTEZ, C.; BECKER, V. TV Digital Interativa: conceitos, desafios e perspectivas para o Brasil. Florionapólis: UFSC, 2005.

PRIOR, M. The immensely inflated news audience: Assessing bias in self-reported news exposure. Public Opinion Quarterly, v. 73, n 1, p. 130-143, 2009.

ROWLEY, T. Moving Beyond Dyadic Ties: A network Theory of Stakeholders Influences. Academy of management Review, v.22, n 4, p. 887-910, 1997.

STROUD, N. J. Polarization and partisan selective exposure. Journal of Communication, v. 60, n. 3, p. 556-576. 2010.

SUCHMAN, M. Managing legitimacy: strategic and institutional approaches. Academy of Management Review. v. 20, p. 571-610,1995.

STEINBERG, E. Stakeholder Theory Exposed. The corporate governance quarterly (HK). 1996.

SUFRAMA 2013. Disponível em: <http://www.teleco.com.br/nrtv1.asp>. Acesso em 19/04/2013.

THALER, A. Principais Processos de Design de Interação e a TV Digital 
Estratégia dos negócios: Obstáculos encontrados para a consolidação da TV Digital no Brasil e seus impactos na cadeia produtiva eletroeletrônica na perspectiva da teoria dos stakeholders

Interativa Brasileira. Dissertação de Mestrado, UFSC, 2011.

WEBSTER, J. G., KSIAZEK, T. B. (2012). The dynamics of audience fragmentation: Public attention in an age of digital media. Journal of Communication, v. $62, \mathrm{n} 1$, p. 39-56. 2012 ,

WEISS, J. W. Business Ethics: a Stakeholder and Issues Management Approach. 2. ed. Forth Worth, Texas: Dryden Press, 1998.

WINDSOR, D. Can Stakeholder Interests be balanced? In: IABS 1999. 10, 1999, Paris. Proceedings... Paris: [s.n], 1999. p. 476-481.

WOOD, D. J. Business and Society. Pittsburgh: Harper Collins, 1990.

ZANCANARO, A. Conhecimento envolvido na construção de conteúdo para TV Digital interativa na Ead. Dissertação De Mestrado, UFSC, 2011. 